Research Article

\title{
Synthesis and Characterization of Zinc Oxide Nanoparticles Using Moringa Leaf Extract
}

\author{
Saka Abel, ${ }^{1}$ Jule Leta Tesfaye,,${ }^{1,2}$ Nagaraj Nagaprasad $\left(\mathbb{D},{ }^{3}\right.$ R. Shanmugam, ${ }^{4}$ \\ L. Priyanka Dwarampudi, ${ }^{5}$ and Ramaswamy Krishnaraj $\mathbb{D}^{2,6}$ \\ ${ }^{1}$ Department of Physics, College of Natural and Computational Science, Dambi Dollo University, Ethiopia \\ ${ }^{2}$ Centre for Excellence-Indigenous Knowledge, Innovative Technology Transfer and Entrepreneurship, \\ Dambi Dollo University, Ethiopia \\ ${ }^{3}$ Department of Mechanical Engineering, ULTRA College of Engineering and Technology, Madurai, Tamil Nadu, India \\ ${ }^{4}$ TIFAC CORE HD, Department of Pharmacognosy, JSS Academy of Higher Education and Research, Ooty, Tamil Nadu, India \\ ${ }^{5}$ Department of Pharmacognosy, JSS Academy of Higher Education and Research, Ooty, Tamil Nadu, India \\ ${ }^{6}$ Department of Mechanical Engineering, College of Engineering and Technology, Dambi Dollo University, Ethiopia
}

Correspondence should be addressed to Ramaswamy Krishnaraj; prof.dr.krishnaraj@dadu.edu.et

Received 8 July 2021; Revised 8 September 2021; Accepted 13 September 2021; Published 1 October 2021

Academic Editor: A. Madhan Kumar

Copyright (c) 2021 Saka Abel et al. This is an open access article distributed under the Creative Commons Attribution License, which permits unrestricted use, distribution, and reproduction in any medium, provided the original work is properly cited.

\begin{abstract}
This paper investigates the technique of biosynthesis of nanoparticles of zinc oxide from the extraction of moringa leaves. Many researchers recognize the use of this method of green culinary technique because it is cost-effective and has no negative impact on the environment; however, this paper focuses on the bacteria chosen for the green synthesis, which was not addressed by many of the researchers. The firmness and reduction of $\mathrm{Zn}$ ions in nanoparticles of zinc oxide were analyzed with a UV-visible spectroscope. Its results show that a wide bandgap was observed in the visible region at a wavelength of 350 nanometers. Extraction of moringa leaves serves as a promising agent for the balance of particle size. The result of medical value shows significant antibacterial activity in contrast to the type of pathogenic bacteria Escherichia coli and Staphylococcus aureus. From the XRD results, there are no further peaks that correspond to impurities that are discovered, demonstrating the great purity of the provided results.
\end{abstract}

\section{Introduction}

Currently, nanotechnology is one of the best dynamic investigations for researchers to endeavor widespread research for the synthesis of nanoparticles by the leaf extract of plants and increase the biosynthesis of inorganic metallic oxide nanoparticles like zinc oxide, copper oxide, and titanium oxide NPs. NPs display absolutely enhanced properties depending on specific features such as size, delivery, and morphology [1]. An eco-friendly green-intermediated preparation of inorganic nanoparticles is a fast increasing research in the member of nanosciences [2] than that of physical method and chemical solution method. Biosynthesis techniques that retain plant extraction have pinched consideration as a humble and feasible alternative to chemical processes and physical techniques [3]. Zinc oxide is selected for the present work. It goes to a cluster of metal oxides for photooxidization and photocatalytic capability alongside chemical solutions and biological types [4]. Zinc oxide NPs have extensive applicable attention because of their antimicrobial, ultraviolet blocking, and maximum catalytic and photochemical actions [4]. Zinc oxide NPs revealed antimicrobial activities even at minor concentrations, appropriate for thin coating applications [5]. Chemical techniques of synthesis of NPs are also excessive in the atmosphere [6]. So, for many causes, mainly for eco-friendly benefits, the green synthesis techniques or green preparation of NPs has been deliberated by scholars [7]. In these new techniques (i.e., green deposition), plants, microbiology, or fungus serve as the root to depose NPs. They specified an effective way to 
feat the biological tools that existed in nature $[8,9]$. Plant life might be broadly used because of its richness, easy obtainability, and eco-friendly compatibility without prompting opposing atmospherical impacts [10].

The processes of preparing nanoparticles from various types of plants are technically simpler than chemical techniques. Hence, organic ingredients play an essential role in the preparation of nanoparticles, and they are taken as unique solutions that might replace with chemical techniques. Floras such as Aloe vera, Glycosmis pentaphylla leaf, Limonia acidissima, and Moringa oleifera are used to prepare zinc oxide nanoparticles. Even if the implication of plants for the formation of NPs has been emphasized inappropriately [11-14], only a few numbers of investigations have been conducted on this area in Ethiopia. Since Ethiopia is regarded by an amazing diversity of medicinal plants, supplementary studies are necessary to be carried out in this repute. The analysis of nanoparticle activities on antibacteria is using gram-positive and gram-negative bacteria. M. oleifera is classified into the family Moringaceae. It is a moderate-sized plant that matures to the length of 5 to 12 meters. The leaves of the Moringa oleifera tree are bi- and trijaunt inherent with the inner elliptical-shaped brochures [15] and serve as a cultural medical plant. Different bodies of it are active in treating different diseases like anemia, blindness, arthritis, hyperthyroidism, rheumatism, epilepsy, Crohn's disease, herpes simplex virus, gout, and sexually transmitted diseases [16-18]. M. oleifera is filled in nourishment due to the presence of essential phytochemicals. The phytochemical profile of its leaves exhibited the presence of essential minerals, vitamins, sterols, anthraquinones, alkaloids, terpenoids, flavonoids, tannins, and saponins [19]. These phytoconstituents lead to anti-inflammatory, antiulcer, antidiabetic [20], anticancer [21], antimicrobial, antioxidant, and antifungal properties [22].

Synthesization of nanoparticles from leaf extraction using plants is simpler to use. It is not toxic, and there is no poison released to the environment. Moreover, it should be replaced with other methods of preparation of nanoparticles. Because of paramount mentioned facts about the medical ideals of this plant, the present study brought a biomimetic approach for the green synthesis of ecofriendly zinc oxide nanoparticles from Moringa oleifera through bioreduction, UV-visible spectroscopy, scanning electron microscopy, X-ray diffraction characterization, and antimicrobial studies.

\section{Material and Methods}

For the preparation of nanoparticles extracted from moringa, zinc nitrate hexahydrate, deionized water was bought from shops of chemicals. All instruments are purified with weak acid like nitric acid and additionally by deionized water then dried up by putting it in the oven before the next procedure. The leaves of Moringa oleifera were collected from Dambi Dollo University, Ethiopia.

2.1. Synthesis of Aqueous Extract from Moringa oleifera Leaves. The fresh leaves of Moringa oleifera (Figure 1) are

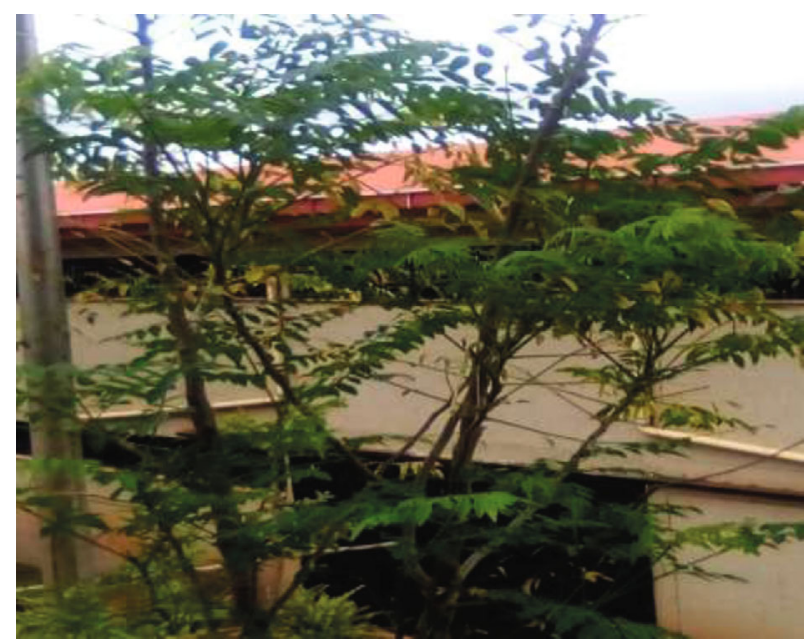

Figure 1: Moringa oleifera tree originally taken from Dambi Dollo University, Ethiopia.

gathered, and new leaves were washed using water to eliminate dirt and dust spots. The leaves of the plant were dried in the air for two weeks because the time at which this study was conducted was the rainy season, and then, leaves were ground with the help of a mortar with pestle till the leaves were well powdered finely. The aqueous extract of Moringa oleifera leaves was prepared using 10 grams of powder of moringa leaves and put to $90 \mathrm{ml}$ of deionized water at $70^{\circ} \mathrm{C}$ to $90^{\circ} \mathrm{C}$ for 20 minutes. The extract was purified through strainer paper. Finally, the filtered solution was kept in the refrigerator at $6^{\circ} \mathrm{C}$ for the next works.

2.2. Synthesis of Zinc Oxide Nanoparticles from Leaf Extraction. The source of zinc ion was zinc nitrate hydroxide used in the present study which was bought from chemical shop, Addis Ababa, Ethiopia. The solution of $\left(\mathrm{Zn}\left(\mathrm{NO}_{3}\right)_{2} \cdot 6 \mathrm{H}_{2} \mathrm{O}\right)$ was prepared in deionized water. For the preparation of zinc oxide NPs, the flask containing $50 \mathrm{ml}$ of zinc nitrate hydroxide $(0.2 \mathrm{M})$ was reacted with $10 \mathrm{~mm}$ of the aqueous leaf extract of Moringa oleifera and stirred using a magnetic stirrer heated at $70^{\circ} \mathrm{C}$ and stirring is nonstop until a homogenous mixture of the solution is attained.

The uniform solution is desiccated in a warm air oven at the temperature of $100-110^{\circ} \mathrm{C}$ for 90 minutes and annealed at $300-350^{\circ} \mathrm{C}$ for $1 \mathrm{~h}$ in a muffle boiler. The particles with yellow color obtained are wrinkled in a metallic mortar and pestle to get green-synthesized zinc oxide nanoparticles.

The crystal phase analysis of the $\mathrm{ZnO}$ nanoparticles was characterized by using the Bruker D8 diffract meter with $\mathrm{CuK} \alpha\left(1.5406 \mathrm{~A}^{\circ}\right)$ radiation occupied at $40 \mathrm{~mA}$ and $40 \mathrm{kV}$. The nanoparticles were scanned, regulating the diffractometer in the $2 \theta$ range of $25-45^{\circ}$ at a step size of 0.12 and scanning rate of $0.6 \mathrm{sec}^{-1}$. The optical properties of the $\mathrm{ZnO}$ nanoparticles were recorded by a Shimadzu UV-3600 plus UV-Vis spectrophotometer with PerkinElmer. The morphology of the films was studied by scanning electron microscopy (SEM) integrated with an X-ray diffraction (XRD) analyzer. 


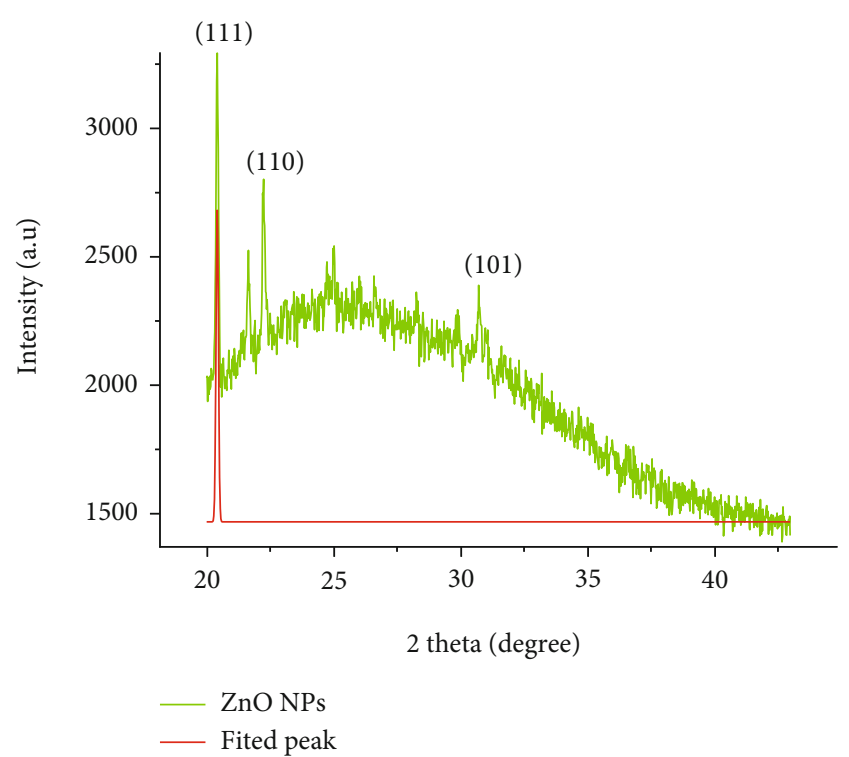

FIgURE 2: X-ray diffraction patterns of ZnO NPs.

\section{Result and Discussion}

3.1. X-Ray Diffraction Analysis of ZnO NPs from Moringa Leaf Extract. X-ray deflection configurations of equipped zinc oxide nanoparticles reveal that all peaks agree with the standard data. The appeared peaks of X-ray diffraction (Figure 2) are wonderfully arranged with the hexagonal crystal structure [23]. The sharpness, as well as peaks having intensity in Figure 2, expresses that the nanoparticles are extremely crystalline. The pattern can be indexed for diffractions from the (111), (110), and (101) planes. There are no other peaks conforming to impurity that is found, revealing the high purity of the prepared outcomes.

By using XRD data, it was created that the peaks are broad; signifying that the crystallites have sizes in the $\mathrm{nm}$ range, and the diameter (D) was calculated using Scherrer's formula

$$
D=\frac{K \lambda}{\beta \cos \theta},
$$

where $K$ stands for Debye Scherrer constant, $\lambda$ is for $\mathrm{X}$ ray wavelength, $\beta$ is the width of the peak of half maximum, and $\theta$ is the diffraction angle [24]. The estimated crystalline size of $\mathrm{ZnO}$ is measured by $\mathrm{X}$-ray diffraction data, and it was obtained around $50 \mathrm{~nm}$.

The calculation of the crystal size of $\mathrm{ZnO}$ nanoparticles is summarized in Table 1.

3.2. UV-Vis Analysis of ZnO NPs from Moringa Leaf Extract. As illustrated in Figure 3, the absorption spectrum of the prepared zinc oxide nanoparticles with the absorption peak nearby is 350 nanometers. It expresses that $\mathrm{ZnO}$ nanoparticles exhibit excitation absorption (at $350 \mathrm{~nm}$ ) due to their huge excitation binding energy at $37^{\circ} \mathrm{C}$. The existed sharp bands of $\mathrm{Zn}$ colloids were perceived at $350 \mathrm{~nm}$, which demonstrates that the $\mathrm{Zn}$ ion is competently reduced by the $M$.
TABLE 1: Comparison of evaluated crystal size $D(\mathrm{~nm})$ by using XRD results.

\begin{tabular}{lccc}
\hline No. & 2 theta (degree) & FWHM (radians) & $D(\mathrm{~nm})$ \\
\hline 1 & 20.41 & 0.095 & 90.51 \\
2 & 23.22 & 7.85 & 1.10 \\
3 & 30.72 & 0.154 & 55.21 \\
4 & 30.81 & 8.62 & 0.98 \\
\hline
\end{tabular}

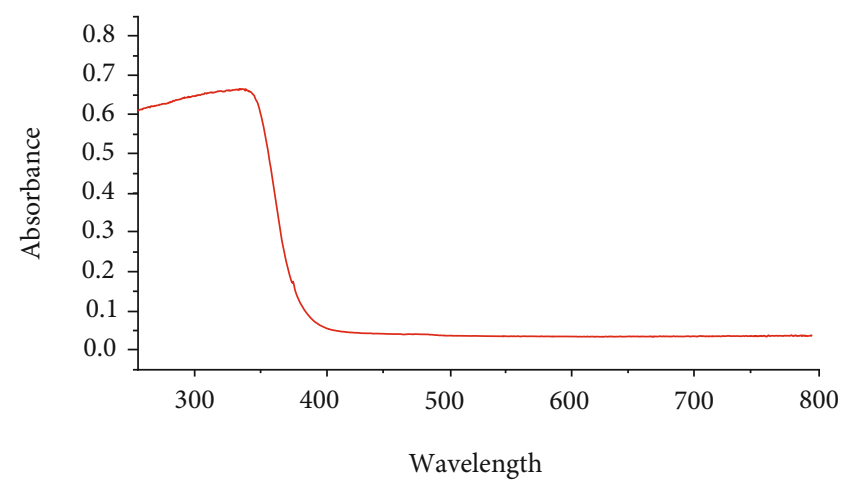

Figure 3: UV-visible analysis of $\mathrm{ZnO}$ nanoparticle.

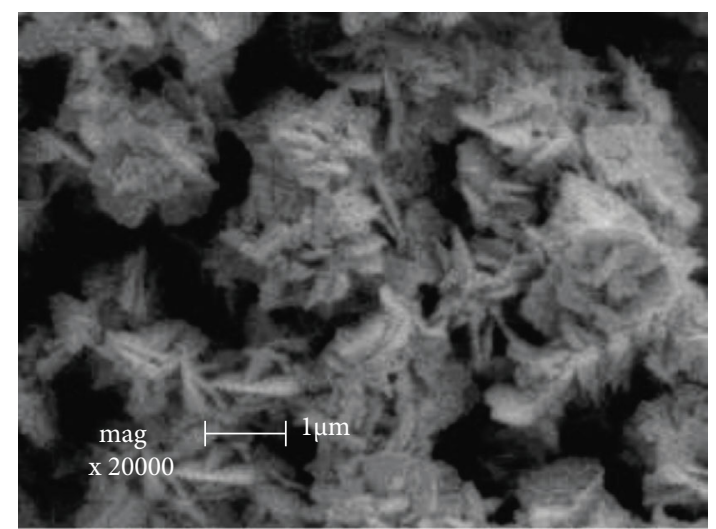

FIGURE 4: Scanning electron microscope images of green deposition of zinc oxide nanoparticles.

oleifera leaf extract. The existence of blue-shifted absorption spectrum is with deference to the large value $(375 \mathrm{~nm})$ of the zinc oxide nanoparticles approved by the wavelength of $350 \mathrm{~nm}$ absorption peak, because of the quantum imprisonment effect, which is in excellent match with the beforehand report [25-31].

3.3. Scanning Electron Microscopy Analysis of ZnO NPs from Moringa Leaf Extracts. Afterward, the confirmation of the sample's X-ray diffraction results was further headed for the scanning electron microscopy study. The size of the crystal, the shape of the crystal, and the morphology of the zinc oxide nanoparticle are clearly shown by the scanning electron microscope image as displayed in Figure 4. Detailed structural characterizations demonstrate that the synthesized products are flower-like shapes and crystal in arrangement, and the measured diameters were about $50 \mathrm{~nm}$. These results also agree with those previously reported [32-49]. 


\section{Conclusion}

The green synthesis of zinc oxide NPs was efficaciously produced from leaf extract of Moringa oleifera. The biosynthesis technique used is modest and easily biodegradable and conducted in a short period. The revealed yellow color indicates the preparation of zinc oxide NPs, which further established the reduction of $\mathrm{Zn}$ ions into $\mathrm{ZnO}$ nanoparticles by using ultraviolet-visible spectroscopy. The ultraviolet spectroscopic absorption peak is at 350 nanometers. XRD and SEM analysis show that the particle property prepared was polycrystalline and had no void and flower-like shape. The antibacterial study demonstrated that the gram-negative $\left(\mathrm{G}^{-}\right)$and gram-positive $\left(\mathrm{G}^{+}\right)$bacteria are profound to the zinc oxide nanoparticles.

\section{Data Availability}

The data used to support the findings of this study are included within the article.

\section{Disclosure}

This study was performed as a part of the employment of the authors.

\section{Conflicts of Interest}

The authors declare that there are no conflicts of interest.

\section{References}

[1] F. Constantinescu and O. A. Boiu Sicuia, "Phytonanotechnology and plant protection," Phyton, p. 245, 2020.

[2] D. Letsholathebe, F. T. Thema, K. Mphale, K. Maabong, and C. Maria Magdalane, "Green synthesis of $\mathrm{ZnO}$ doped_Moringa oleifera leaf_extract using Titon yellow dye for photocatalytic applications," Materials Today: Proceedings, vol. 36, pp. 475-479, 2021.

[3] A. H. Alrajhi, N. M. Ahmed, M. Al Shafouri, and M. A. Almessiere, "Green synthesis of zinc oxide nanoparticles using salvia officials extract," Materials Science in Semiconductor Processing, vol. 125, p. 105641, 2021.

[4] F. Adam, A. Himawan, M. Aswad, S. Ilyas, M. A. Anugrah, and D. Tahir, "Green synthesis of zinc oxide nanoparticles using Moringa oleifera l. water extract and its photocatalytic evaluation," Journal of Physics: Conference Series, vol. 1763, p. 012002, 2021.

[5] I. Ngom, B. D. Ngom, J. Sackey, and S. Khamlich, "Biosynthesis of zinc oxide nanoparticles using extracts of_Moringa Oleifera_ : Structural \& optical properties," Materials Today: Proceedings, vol. 36, pp. 526-533, 2021.

[6] J. K. Akintunde, T. I. Farai, M. R. Arogundade, and J. T. Adeleke, "Biogenic zinc-oxide nanoparticles of_Moringa oleifera_ leaves abrogates rotenone induced neuroendocrine toxicity by regulation of oxidative stress and acetylcholinesterase activity," Biochemistry and Biophysics Reports, vol. 26, p. 100999, 2021.

[7] S. Thakur, M. Shandilya, and G. Guleria, "Appraisement of antimicrobial zinc oxide nanoparticles through Cannabis Jatropha curcasa Alovera and Tinosporacordifolia leaves by green synthesis process," Journal of Environmental Chemical Engineering, vol. 9, no. 1, p. 104882, 2021.

[8] H. M. Mehwish, M. S. R. Rajoka, Y. Xiong et al., "Green synthesis of a silver nanoparticle using _Moringa oleifera_ seed and its applications for antimicrobial and sun-light mediated photocatalytic water detoxification," Journal of Environmental Chemical Engineering, vol. 9, no. 4, p. 105290, 2021.

[9] A. M. Awwad, M. W. Amer, N. M. Salem, and A. O. Abdeen, "Green synthesis of zinc oxide nanoparticles ( $\mathrm{ZnO}-\mathrm{NPs}$ ) using Ailanthus altissima fruit extracts and antibacterial activity," Chemistry International, vol. 6, pp. 151-159, 2020.

[10] R. Verma, A. Chauhan, M. Shandilya, X. Li, R. Kumar, and S. Kulshrestha, "Antimicrobial potential of Ag-doped $\mathrm{ZnO}$ nanostructure synthesized by the green method using Moringa oleifera extract," Journal of Environmental Chemical Engineering, vol. 8, p. 103730, 2020.

[11] I. Ngom, N. M. Ndiaye, A. Fall, M. Bakayoko, B. D. Ngom, and M. Maaza, "On the use of Moringa oleifera leaves extract for the biosynthesis of $\mathrm{NiO}$ and $\mathrm{ZnO}$ nanoparticles," MRS Advances, vol. 5, no. 21-22, pp. 1145-1155, 2020.

[12] Y. Pratiwi, Y. Yulizar, and D. O. B. Apriandanu, "Preparation of $\mathrm{ZnO}$ nanoparticles in n-hexane-water system using Moringa oliefera leaf extract and its photodegradation activity," Materials Science and Engineering, vol. 763, p. 012022, 2020.

[13] M. Irfan, H. Munir, and H. Ismail, "Moringa oleifera gum based silver and zinc oxide nanoparticles: green synthesis, characterization and their antibacterial potential against MRSA," Biomaterials Research, vol. 25, no. 1, pp. 1-8, 2021.

[14] A. Fatiqin, H. Amrulloh, and W. Simanjuntak, "Green synthesis of $\mathrm{MgO}$ nanoparticles using Moringa oleifera leaf aqueous extract for antibacterial activity," Bulletin of the Chemical Society of Ethiopia, vol. 35, no. 1, pp. 161-170, 2021.

[15] S. D. Chavan, S. R. Mirgane, and R. D. More, "Biosynthesis of zinc oxide nanoparticles by using $M$. oleifera leaves extract and its effect against pathogenic bacteria," Journal of Engineering Sciences, vol. 11, pp. 1413-1416, 2020.

[16] C. S. Espenti, A. G. Rama Krishna, and Y. V. Rami Reddy, "Green biosynthesis of $\mathrm{ZnO}$ nanomaterials and their antibacterial activity by using Moringa oleifera root aqueous extract," SN Applied Sciences, vol. 2, no. 8, pp. 1-11, 2020.

[17] K. D. Dejen, E. A. Zereffa, H. A. Murthy, and A. Merga, "Synthesis of $\mathrm{ZnO}$ and $\mathrm{ZnO} / \mathrm{PVA}$ nanocomposite using aqueous Moringa oleifeira leaf extract template: antibacterial and electrochemical activities," Reviews on Advanced Materials Science, vol. 59, no. 1, pp. 464-476, 2020.

[18] M. Bandeira, M. Giovanela, M. Roesch-Ely, D. M. Devine, and J. da Silva Crespo, "Green synthesis of zinc oxide nanoparticles: a review of the synthesis methodology and mechanism of formation," Sustainable Chemistry and Pharmacy, vol. 15, p. 100223, 2020.

[19] V. Srivastava and A. K. Choubey, "Kinetic and isothermal study of effect of transition metal doping on adsorptive property of zinc oxide nanoparticles synthesized via green route using Moringa oleifera leaf extract," Materials Research Express, vol. 6, p. 1250i7, 2019.

[20] J. T. R. K. Timah, D. Cimanggis, B. T. N. Nasional, K. Puspitek, and T. S. Serpong, "GREEN synthesis nanopartikel Zno menggunakan media ekstrak daun tin (Ficus carica Linn)," Jurnal Kimia dan Kemasan, vol. 42, no. 1, pp. 1-6, 2020.

[21] V. Sannasi and K. Subbian, "Influence of Moringa oleifera gum on two polymorphs synthesis of $\mathrm{MnO} 2$ and evaluation of the 
pseudo-capacitance activity," Journal of Materials Science: Materials in Electronics, vol. 31, no. 19, pp. 17120-17132, 2020.

[22] L. F. A. Raj and J. E, "Biosynthesis and characterization of zinc oxide nanoparticles Using Root Extract of Zingiber Officinale," Oriental Journal of Chemistry, vol. 31, no. 1, pp. 51-56, 2015.

[23] D. Jagwani and P. Hari Krishna, "Nature's nano-assets: Green synthesis, characterization techniques and applications - A graphical review," Materials Today: Proceeding, vol. 46, no. 6, pp. 2307-2317, 2021.

[24] S. Drummer, T. Madzimbamuto, and M. Chowdhury, "Green synthesis of transition-metal nanoparticles and their oxides: a review," Materials, vol. 14, no. 11, p. 2700, 2021.

[25] M. Hazaa, M. Alm-Eldin, A. E. Ibrahim et al., "Biosynthesis of silver nanoparticles using Borago officinslis leaf extract, characterization and larvicidal activity against cotton leaf worm, Spodoptera littoralis (Bosid)," International Journal of Tropical Insect Science, vol. 41, no. 1, pp. 145-156, 2021.

[26] D. Tripathi, K. K. Rai, and S. Pandey-Rai, "Impact of green synthesized WcAgNPs on in-vitro plant regeneration and withanolides production by inducing key biosynthetic genes in Withania coagulans," Plant Cell Reports, vol. 40, no. 2, pp. 283-299, 2021.

[27] S. Abel, J. L. Tesfaye, R. Shanmugam et al., "Green synthesis and characterizations of zinc oxide $(\mathrm{ZnO})$ nanoparticles using aqueous leaf extracts of coffee (Coffea arabica) and its application in environmental toxicity reduction," Journal of Nanomaterials, vol. 2021, Article ID 3413350, 6 pages, 2021.

[28] H. Sadiq, F. Sher, S. Sehar et al., "Green synthesis of $\mathrm{ZnO}$ nanoparticles from Syzygium Cumini leaves extract with robust photocatalysis applications," Journal of Molecular Liquids, vol. 335, p. 116567, 2021.

[29] S. Abel, J. L. Tesfaye, B. Fikadu et al., "Application of Titanium Dioxide Nanoparticles Synthesized by Sol-Gel Methods in Wastewater Treatment," Journal of Nanomaterials, vol. 2021, Article ID 3039761, 6 pages, 2021.

[30] B. Bekele, A. Degefa, F. Tesgera et al., "Green versus chemical precipitation methods of preparing zinc oxide nanoparticles and investigation of antimicrobial propertiest," Journal of Nanomaterials, vol. 2021, Article ID 9210817, 10 pages, 2021.

[31] A. Degefa, B. Bekele, L. T. Jule et al., "Green Synthesis, Characterization of Zinc Oxide Nanoparticles, and Examination of Properties for Dye-Sensitive Solar Cells Using Various Vegetable Extracts," Journal of Nanomaterials, vol. 2021, Article ID 3941923, 9 pages, 2021.

[32] K. S. Y. Al Baloushi, Green Synthesis, Characterization, Antioxidant and Anticancer Activities of Silver Nanoparticle Using Moringa Peregrina Leaf Extract, Master Thesis of United Arab Emirates University, 2020.

[33] A. Iranbakhsh, Z. O. Ardebili, and N. O. Ardebili, "Synthesis and characterization of zinc oxide nanoparticles and their impact on plants," in Plant Responses to Nanomaterials: Recent Interventions, and Physiological and Biochemical Responses, pp. 33-93, Nanotechnology in Life Science, Springer, 2021.

[34] R. Krishnaraj, "Investigation on the effect of thermo physical properties on heat and mass transfer-review," International Journal of Applied Environmental Sciences, vol. 9, no. 4, pp. 1893-1900, 2014.
[35] C. N. Anil Kumar, R. Krishnaraj, M. Sakthivel, and M. Arularasu, "Implementation of safety education program for material handling equipment in construction sites and its effectiveness analysis using T-test," International Journal of Applied Environmental Sciences, vol. 8, no. 15, pp. 19611969, 2013.

[36] L. T. Jule, R. Krishnaraj, N. Nagaprasad, B. Stalin, V. Vignesh, and T. Amuthan, "Evaluate the structural and thermal analysis of solid and cross drilled rotor by using finite element analysis," Materials Today: Proceedings, vol. 45, 2021.

[37] B. Kassa, J. Leta Tesfaye, B. Bulcha et al., "Effect of Manganese Ions on Spectroscopic and Insulating Properties of Aluminophosphate Glasses," Advances in Materials Science and Engineering, vol. 2021, Article ID 6253069, 11 pages, 2021.

[38] S. Abel, J. Leta Tesfaye, R. Kiran et al., "Studying the effect of metallic precursor concentration on the structural, optical, and morphological properties of zinc sulfide thin films in photovoltaic cell applications," Advances in Materials Science and Engineering, vol. 2021, Article ID 7443664, 6 pages, 2021.

[39] L. Tesfaye, B. Bekele, A. Saka, N. Nagaprasad, K. Sivaramasundaram, and R. Krishnaraj, "Investigating spectroscopic and structural properties of $\mathrm{Cr}$ doped $\mathrm{TiO}_{2}$ NPs synthesized through sol gel deposition technique," Tierärztliche Praxis, vol. 41, pp. 860-872, 2021.

[40] L. Tesfaye Jule, K. Ramaswamy, N. Nagaprasad, V. Shanmugam, and V. Vignesh, "Design and analysis of serial drilled hole in composite material," Materials Today: Proceedings, vol. 45, pp. 5759-5763, 2021.

[41] T. Amuthan, N. Nagaprasad, R. Krishnaraj, V. Narasimharaj, B. Stalin, and V. Vignesh, "Experimental Study of Mechanical Properties of AA6061 and AA7075 Alloy Joints Using Friction Stir Welding," Materials Today: Proceedings, vol. 45, 2021.

[42] E. K. Subramaniam, M. Sakthivel, K. Kanthavel, R. Krishnaraj, M. G. Deepan Marudachalam, and R. Palani, "Overall resource effectiveness, cycle time reduction \& capacity improvements," International Journal of Scientific and Engineering Research, vol. 2, no. 8, pp. 1-5, 2011.

[43] R. Sathiyamoorthy and R. Krishnaraj, "Optimization of cellular layout under dynamic demand environment by simulated annealing," International Journal of Scientific and Engineering Research, vol. 3, no. 10, pp. 1-7, 2012.

[44] V. M. M. Thilak, R. Krishnaraj, M. Sakthivel, K. Kanthavel, M. Marudachalam, and R. Palani, "Transient thermal and structural analysis of the rotor disc of disc brake," International Journal of Scientific and Engineering Research, vol. 2, no. 8, pp. 2-5, 2011.

[45] S. Varatharajan, R. Krishnaraj, M. Sakthivel, K. Kanthavel, M. G. Deepan Marudachalam, and R. Palani, "Design and analysis of single disc machine top and bottom cover," International Journal of Scientific and Engineering Research, vol. 2, no. 8, pp. 1-6, 2011.

[46] C. M. Balamurugan, R. Krishnaraj, M. Sakthivel, K. Kanthavel, D. Marudachalam, and R. Palani, "Computer aided modeling and optimization of crankshaft," International Journal of Scientific and Engineering Research, vol. 2, no. 8, pp. 2-7, 2011.

[47] M. Vyshakh, R. Krishnaraj, A. P. Sayooj, and M. Afzal, "Experimental investigation on aluminium gravity die casting," International Journal of Applied Environmental Sciences, vol. 9, no. 2, pp. 213-222, 2014. 
[48] M. Deepu, R. Krishnaraj, D. Karthik, and N. M. Binoj, "Cycle time optimization of Different Parameters for Biohydrogen Production by Klebsiella oxytoca ATCC 13182," International Journal of Applied Environmental Sciences, vol. 9, no. 5, pp. 229-237, 2014.

[49] V. S. Arun, R. Krishnaraj, M. N. Rohit, and V. Mohan, "Optimising rejection rate of laser diamond sawing using Taguchi method," International Journal of Applied Environmental Sciences, vol. 9, no. 2, pp. 223-228, 2014. 